\title{
Identification of critical factors for the implementation of reverse logistics in the manufacturing industry of Pakistan
}

Identification of critical factors

\author{
Yousaf Ali, Khaqan Zeb, Abdul Haseeb Khan Babar and \\ Muhammad Asees Awan \\ School of Management Sciences, Ghulam Ishaq Khan Institute of Engineering \\ Sciences and Technology, Topi, Pakistan
}

\begin{abstract}
Purpose - The purpose of this research is to identify major barriers to the implementation of reverse logistics (RL). Also, the study addresses best practices among reuse, remanufacture, recycling, refurbishment and repair as alternatives for RL processes.

Design/methodology/approach - This study targets supply chain management experts for their opinions regarding the identification of critical barriers and alternatives for RL implementation. Their opinions were extracted through a Web questionnaire based on 14 criteria with 5 alternatives. The tools of multi-criteria decision-making are used for analysis, i.e. fuzzy VIKOR and fuzzy TOPSIS.
\end{abstract}

Findings - The results indicate that lack of recognition of competitive advantage to be gained through RL practice is the most critical barrier to RL implementation. The least barrier or major facilitator for RL is "supportive initiative for end-of-life products." The top-ranked alternative in this study is reuse followed by remanufacturing. The least important alternative is "repair" in the case of Pakistan. These alternatives are ranked based on " $q$ values" derived through fuzzy VIKOR.

Research limitations/implications - The results of this study can only be generalized for the manufacturing sector of Pakistan during the period of the study.

Practical implications - The findings of this study will assist managers in deploying the best practices concerning RL.

Originality/value - Fuzzy VIKOR and fuzzy TOPSIS have not been applied to RL alternatives in previous research.

Keywords Fuzzy TOPSIS, Fuzzy VIKOR, Manufacturing sector, Pakistan, Reverse logistics, Fuzzy set theory, MCDM

Paper type Research paper

(C) Yousaf Ali, Khaqan Zeb, Abdul Haseeb Khan Babar and Muhammad Asees Awan. Published in Journal of Defense Analytics and Logistics. Published by Emerald Publishing Limited. This article is published under the Creative Commons Attribution (CC BY 4.0) licence. Anyone may reproduce, distribute, translate and create derivative works of this article (for both commercial and non-commercial purposes), subject to full attribution to the original publication and authors. The full terms of this licence maybe seen at http://creativecommons.org/licences/by/4.0/ legalcode

The authors would like to thank editor and the anonymous reviewers for their valuable comments and recommendations.

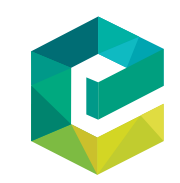

Journal of Defense Analytics and Logistics

Vol. 5 No. 1,2021 pp. $95-112$

Emerald Publishing Limited 2399-6439 DOI 10.1108/JDAL-07-2020-0013 


\section{JDAL 5,1}

\section{Introduction}

In today's manufacturing world, mega-competition on the global scale has led to radical transformations in supply chains. Over the past few years, the community of supply chain management researchers and practitioners has given increasing importance to reverse logistics (RL). The academic literature in marketing and supply chain has given substantial attention to RL, as it reflects the channel distribution ability of a firm (Horvath et al., 2005). For both firms and their suppliers, RL has major cost implications in the supply chain (Daugherty et al., 2005). To remain competitive, it has become necessary for many firms to adopt RL practices in their supply chains.

There are very few empirical studies related to the reverse flow of products in a supply chain, despite the due consideration given to RL by both practitioners and researchers (Srivastava and Srivastava, 2006). In recent practice, RL is being adopted for strategic reasons by many manufacturing companies. These reasons include to improve the corporate social image and to gain the economic benefits of RL (Govindan et al., 2015). In the best circumstances, the implementation of RL may lead to reduced operational costs and higher sales revenue. However, many barriers limit RL implementation. These barriers include difficulty with supply chain members, lack of the necessary technical skills and uncertain profitability (Subramanian and Ramanathan, 2012). Thus, there is a need to collect information on the barriers to RL, and how to overcome them, from practitioners.

Pakistan has a developing economy with great potential to grow. It is currently the 13th largest manufacturing country in the world. About $20 \%$ of the gross domestic product (GDP) comes from the manufacturing sector. The sector has registered a $3.4 \%$ average annual growth from 2011 to 2016. In 2012, the large-scale manufacturing sector in Pakistan grew by $2 \%$ and small-scale manufacturing (SME) grew by $8 \%$ [1].

Despite its environmental and economic relevance in developing countries, limited research has been conducted on RL. The available theory and literature on the implementation and management of RL are limited, although the concept is gaining popularity in practice. In the majority of developing countries, manufacturers ignore RL. This appears to be driven by more focus on changes in functional priorities, the minimal interest of top management and insufficient commitment (Gunasekaran and Ngai, 2012). Issues related to damaged goods and quality problems present substantial challenges for RL processes. This is reflected in the design of RL networks, where quantity, quality and arrival time of returns are of paramount importance (Srivastava and Srivastava, 2006). The practices of RL vary from company to company and by channel position within the supply chain. In developed countries, more elaborate RL systems exist because of a greater ability to recover value from returned products. However, RL is used less in developing countries because of several barriers. This appears to be the case in Pakistan, with RL underused compared to its prevalence in developed countries.

In alignment with the abovementioned discussion, the objective of this research is to provide critical insights and determine the most critical barriers to the implementation of RL in the case of Pakistan. The second objective of this study is to determine the best alternative for RL implementation to overcome these barriers. To address the mentioned objectives, this research uses multi-criteria decision-making (MCDM) techniques, i.e. fuzzy VIKOR (VIseKriterijumska Optimizacija I Kompromisno Resenje) and fuzzy TOPSIS (Technique for Order Preference by Similarity to Ideal Solution). Manufacturing technique for order performance companies in Pakistan have apparently not overcome the barriers that hinder the implementation of RL. This may be because of a lack of knowledge about strategies and practices that support the use of RL. To support broader adoption of RL in Pakistan, this study tries to identify the most critical barriers and best alternative practices for RL implementation. 
The rest of this paper is organized as follows: Section 2 reviews the related literature on RL; Sections 3 and 4 describe the research methodology including a comparison of fuzzy VIKOR and fuzzy TOPSIS; Section 5 presents the results and discussion of the research; and finally, Sections 6 and 7 describe conclusions and directions for future research.

\section{Literature review}

The practice of RL has evolved over time and its definition has changed accordingly in the research literature. The earliest definition of RL describes it as a reverse flow of goods (Murphy and Poist, 1989). As RL developed, environmental concepts were added to its definition (Carter and Ellram, 1998). After this refinement, it was defined as the cost-effective flow of finished goods from the point of consumption to the point of origin for recapturing value or disposal through effective planning (Rogers and Tibben-Lembke, 1999a). The concept of RL deals with the collection and transportation of used products and packages (Mutha and Pokharel, 2009). Researchers have characterized the process of RL by subordinate processes of collection, inspection, reprocessing, disposal and re-distribution of products (Fleischmann et al., 2000). These key processes involved in RL are depicted in Figure 1.

RL processes begin where forward logistics end. The first step in RL acquires used products from the end customer (Guide and Van Wassenhove, 2001). After the acquisition process, the used products are delivered to different facilities for inspection, sorting and disposition (Fleischmann et al., 2003). For the collection of the used products, three methods have been defined in scholarly studies. These methods include collection from retailers, collection from end customers and collection by a third-party logistics provider (Kumar and Putnam, 2008). After the collection process, the used products are sorted into categories through an inspection process. The outcome of the sorting mostly depends on factors like the cost of transportation, disposal, dismantling and quality of the product (Zikopoulos and Tagaras, 2007). For the disposition process, three alternatives are adopted, i.e. recovery of product, reuse and waste management (Thierry et al., 1995). These three alternatives are constantly in flux because of evolving technological developments. They currently include upgrading of products, recovery of materials and advanced waste treatment practices (Krikke, 2011). Effective implementation of RL processes can reduce costs of operations, enhance revenue and thus generate additional profits (Poist, 2000).

However, there is a high level of uncertainty in planning, forecasting, allocation of capacity and resources for handling and controlling the reverse flows in a supply chain

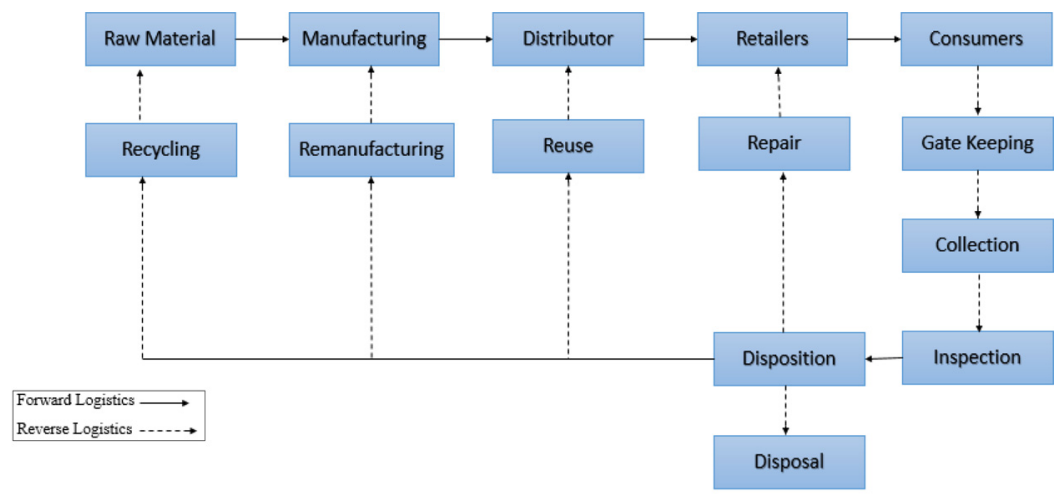

Source: Fleischmann et al. (2000)

Identification of critical factors

Figure 1. Basic flow of reverse and forward logistics 


\section{JDAL 5,1}

98

(Tibben-Lembke and Rogers, 2002). Products can have different lifecycles and varying replacement policies based on the user. This can lead to systematic variation and uncertainty in the volume of returned items over time. Moreover, RL flows from many origins to one destination, whereas the converse is true for forward logistics flows. This type of difference between forward and RL makes it difficult to integrate both into a single supply chain (Fleischmann et al., 1997). There are other differences between forward and RL that make their integration difficult. A number of these differences are summarized in Table 1.

Because of shorter product life cycles and an increase in the use of consignment inventory, RL has become a necessity for companies. Furthermore, there is an increasing trend of returning products from customers that has made the use of RL more advantageous (Daugherty et al., 2001). Therefore, due concentration is given to RL as a strategic capability not only to improve profit directly but also to enhance the level of customer satisfaction (Richey et al., 2004). Moreover, firms with larger volumes of returning products are left with no choice but to consider RL processes (Stock and Mulki, 2009). However, in RL processes, retail managers often play a vital role in determining the cost-saving procedures for returned products, which in turn determines the efficiency of the overall RL system (Horvath et al., 2005).

Globalization in the most recent decade brought access to knowledge, capital and technology from developed countries to the least developed countries. However, despite accelerating economic growth, RL is still at an early stage of maturity in these countries (Hung Lau and Wang, 2009). Despite the vital importance of RL, the literature on it is very limited, especially in the manufacturing area (Somuyiwa and Adebayo, 2014). However, some studies on RL in developing countries do exist. For instance, one study of RL is mainly focused on developing countries including India and Malaysia (Sharma et al., 2011). Moreover, Oleveira et al. (2019) investigates major barriers in circular economy supply chains of expanded polystyrene packaging from a Brazilian perspective. These findings highlighted the major components of efficient reverse logistic strategies in polystyrene recycling in Brazil. Lamba et al. (2019) uses fuzzy analytic hierarchy process to prioritize barriers in RL in an e-commerce

\begin{tabular}{|c|c|}
\hline Forward logistics & Reverse logistics \\
\hline The quality of the product is uniform & e quality of the product is not uniform \\
\hline The option for disposition of a product is clear & The option for disposition of a product is not clear \\
\hline Product routing in unambiguous & Product routing is ambiguous \\
\hline $\begin{array}{l}\text { Different points at which cost is involved is easily } \\
\text { understood }\end{array}$ & $\begin{array}{l}\text { Different points at which cost is involved is not easily } \\
\text { understood }\end{array}$ \\
\hline The distribution channels are standardized & The distribution channels are exception driven \\
\hline Products are packaged in a uniform process & Often the product packaging is damaged \\
\hline pricing product is uniform & The process of pricing product is not uniform \\
\hline If i 1 & The management of inventory is not consistent \\
\hline roduct is easily man & $\begin{array}{l}\text { The life cycle of the product in this process is less } \\
\text { likely to be managed }\end{array}$ \\
\hline $\begin{array}{l}\text { Issues related to financial management are visible } \\
\text { and clear }\end{array}$ & Issues related to financial management are not clear \\
\hline $\begin{array}{l}\text { The type of involvement of negotiation between } \\
\text { different parties is straightforward }\end{array}$ & $\begin{array}{l}\text { The type of involvement of negotiation between } \\
\text { different parties is less straightforward }\end{array}$ \\
\hline Forecasting is done in the simplest way & Forecasting for RL process is much more difficult \\
\hline Transportation involved is one way & Transportation involved from many to only one \\
\hline The visibility of the process is highly & The visibility of the process is much less transparent \\
\hline
\end{tabular}

Table 1.

Generalized form of the difference between the process of forwarding and reverse logistics

Source: Tibben-Lembke and Rogers (2002) 
supply chain. These results emphasize that a lack of investment and a lack of understanding of different practices are substantial barriers to RL implementation in e-commerce. Phochanikorn et al. (2019) uses fuzzy MCDM to analyze barriers to RL in the palm oil industry in Thailand. This analysis resulted in flexible decision strategies for both the short- and long term.

Research related to RL seems to have been largely ignored in Pakistan. Pakistan has a developing economy, with the manufacturing sector having substantial importance. In 2011, manufacturing contributed about 15\% to Pakistan's GDP (World Bank Report, 2012) [2]. According to the Ministry of Commerce of Pakistan, in the year 2012, the major manufacturing industries of Pakistan are textiles, chemicals, machinery and tobacco [3]. The manufacturing sector of the country is expected to grow at $6.2 \%$ as compared to the year 2016-2017 [4], which was 5.8\%. The growth rate of various manufacturing sectors for the year 2016-2017 is given in Table 2.

Practices related to green manufacturing and green supply chains are being implemented in China through legislation. However, there is also pressure from the customer side as stakeholders (Huang et al., 2013). Different barriers have been identified for RL implementation in developing countries. These are lack of government laws and regulating authority (Bouzon et al., 2015a; Hung Lau and Wang, 2009); lack of public awareness of environmental issues (Kannan et al., 2014); resource scarcity, lack of leadership awareness of financial and economic gains (Eltayeb et al., 2011); a limited number of markets and end of life (EOL) recovery issues (Rahimifard et al., 2009).

A research study conducted in Greece concluded that the main barriers to RL systems are complications arising in a company's operation through RL and lack of economic justification for investment (Kapetanopoulou and Tagaras, 2011). The major impediments highlighted for the automobile industry are the lack of supply chain coordination and integration. Likewise, in Bernon et al. (2013) managers' resistance to change, incompatibility of Information Technology (IT) systems and the lack of willingness to share cost information are identified as major roadblocks for product return. Similarly, Abdulrahman et al. (2014) found impediments because of an inability to acquire a monitoring system for returns, low commitment and absence of RL expertise. The research in the automotive industry shows that lack of expertise, the minimal interest of top management, high cost in financial and human resources and the lack of technological systems are the main barriers at the internal level. Whereas, the reluctance of social actors, perception of poor quality products, government and competitor reluctance are some of the obstacles at the external level (González-Torre et al., 2010).

Developed areas such as the USA, Europe and Japan have implemented refined concepts for RL, whereas developing countries practice it at a minor level. According to Locke and Golden-Biddle (1997), the existing social convention can be used to derive specific queries

Identification of critical factors

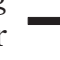


JDAL 5,1

related to any research with aid of the establishment of grounded theory and from these results novel concepts can be introduced (Locke and Golden-Biddle, 1997). A few research studies in China, India and Brazil have investigated factors affecting practices of RL (Hung Lau and Wang, 2009; Erol et al., 2010; Sajan and Sridharan, 2015). However, in our research, we found no prior research in the case of Pakistan regarding barriers to RL implementation. Therefore, this study covers the literature gap regarding the barriers to implementation of RL through MCDM techniques in the case of Pakistan.

MCDM techniques are applied in many domains to solve important problems (Elomda et al., 2013; Ali et al., 2020a, 2020b). In the last few decades, MCDM techniques have become an important branch of operation research (Figueira et al., 2004; Babar et al., 2020). MCDM techniques have enabled decision-makers in the present era to make effective models and decisions in uncertain situations (Nădăban et al., 2016; Ali et al., 2019a, 2019b).

A well-known technique for MCDM is "technique for order performance to ideal solution" (TOPSIS) that was first proposed by Hwang and Yoon (Hwang and Yoon, 1981). The simple TOPSIS technique deals with the principle of selecting an alternative from a positive and negative ideal solution (Yavuz, 2016; Khan et al., 2020). TOPSIS has been used in a fuzzy environment using triangular fuzzy numbers (Chen, 2000). VIsekriterijumska optimizacija i KOmpromisno Resenje (VIKOR) is a tool for MCDM used for decision-making problems that contain criteria that conflict with each other (Opricovic, 1998). The choice of an alternative using VIKOR is determined through a ranking index, i.e. closeness to the ideal solution. The first paper in which VIKOR is used as a methodological tool was published in 2002 (Chang, 2014; Ali et al., 2019a, 2019b).

In this paper, we discuss barriers to the implementation of RL and the most feasible alternatives to overcome this problem for the manufacturing sector of Pakistan. The five alternatives that have been chosen for this study are reuse, remanufacturing, refurbishment, recycle and repair. We identify 14 criteria related to RL barriers. Some of the barriers are lack of IT system standards, lack of personnel technical skills, low recognition of competitive advantage through RL, lack of expert at the management level and lower waste management practices. Likewise, poor relations with suppliers, inconsistent quality of raw materials and uncertainty related to economic issues posed some challenges to a manufacturing organization to adapt the practice of RL. Also, in most of the developing countries, there is rarely any awareness at a public level about RL practices. In addition, there are few initiatives for EOL products. These are some of the barriers that will be used as criteria in this study. Finally, because of these multiple criteria and multiple alternatives, MCDM approaches such as fuzzy VIKOR and fuzzy TOPSIS are appropriate methods to interpret and analyze the data.

\section{Data collection and research methodology}

In this section, the methodology used, i.e. fuzzy VIKOR and fuzzy TOPSIS techniques are briefly discussed. In addition, we briefly summarize our data collection process.

\subsection{Data collection}

A web-based questionnaire was created for data collection, which was then distributed among thirty experts. The first part of the questionnaire comprised demographic questions and the second part consisted of assigning weights to different criteria affecting RL practices based on the expert's opinion. The final part of the questionnaire consisted of rating the different alternatives against the proposed criteria based on the expert's opinion. A seven-point scale of linguistics variables was used for criteria evaluation. Barriers were used as criteria against each alternative (negative attributes) and respondents were asked to choose the most important 
alternative in terms of having a low barrier toward its implementation. There were a total of five alternatives ranked based on 14 criteria with priority set by participants in a rating form.

Twenty participants were supply chain and logistics managers, working in the different manufacturing sectors of Pakistan, i.e. English biscuits manufacturer, Qarshi Group of Industries, Bestway group, Engro fertilizers, etc. Most of the respondents belonged to medium and large-scale industries of Pakistan. Ten participants were related to well-reputed academic institutes, i.e. Lahore University of Management Sciences, Ghulam Ishaq Khan Institute of Engineering Sciences and Technology, National University of Science and Technology, etc. For each academic expert, a minimum threshold of five years teaching experience with three international publications was set, whereas for industrial professionals, five years of professional experience was the threshold. The technique used is discussed briefly below.

\subsection{Fuzzy TOPSIS}

TOPSIS is extended to the fuzzy environment for group decision-making. The linguistic variables used for rating and weighting of criteria are given in Tables 3 and 4 .

TOPSIS under the fuzzy environment can be calculated through the following steps (Ali et al., 2020a, 2020b):

Step 1: The committee of decision-makers is formed. The evaluation criteria are described to the participants. The group members will make decisions based on the criteria given. The opinion of experts was collected through a questionnaire. Define $Z$ as the number of experts, $n$ as the number of alternatives and $m$ as the number of criteria.

Step 2: To find weights of each criterion and rating of alternative against each criterion, select appropriate linguistic variables. Weight will be assigned to the responses obtained from decision-makers. Define $\tilde{y}_{\mathrm{i} j}^{k}$ as the fuzzy rating for the $i$ th alternative, in the $j$ th criteria assigned by the $k$ th decision-maker. Define $\tilde{w}_{j}^{k}$ as the fuzzy weight assigned to the $j$ th

\begin{tabular}{lrr}
\hline Linguistic variables & \multicolumn{1}{c}{ Weights } & \\
\hline Very low (VL) & $(0,0,0.1)$ & \\
Low (L) & $(0,0.1,0.3)$ & \\
Medium low (ML) & $(0.1,0.3,0.5)$ & Table 3. \\
Medium (M) & $(0.3,0.5,0.7)$ & Importance of weight \\
Medium high (MH) & $(0.5,0.7,0.9)$ & fmr linguistic \\
High (H) & $(0.7,0.9,1.0)$ & voriables \\
Very high (VH) & $(0.9,1.0,1.0)$ & varion \\
\hline
\end{tabular}

Identification of critical factors

101

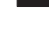


JDAL

5,1

criteria by the $k$ th decision-maker. The overall fuzzy criteria weights $\tilde{w}_{j}$ and alternative ratings $\tilde{y}_{i j}$ can be calculated as follows:

$$
\tilde{y}_{i j}=\frac{1}{Z}\left(\tilde{y}_{\mathrm{ij}}^{1} \oplus \tilde{y}_{\mathrm{i} j}^{2} \oplus \ldots \oplus \tilde{y}_{\mathrm{ij}}^{k} \oplus \ldots \oplus \tilde{y}_{\mathrm{ij}}^{Z}\right)
$$

$$
\tilde{w}_{j}=\frac{1}{Z}\left(\tilde{w}_{j}^{1} \oplus \tilde{w}_{j}^{2} \oplus \ldots \oplus \tilde{w}_{j}^{k} \oplus \ldots \oplus \tilde{w}_{j}^{Z}\right)
$$

Step 3: Construct a fuzzy decision matrix. In matrix format, a fuzzy multi-criteria group decision-making problem can be expressed through $\tilde{D}$ and $\tilde{w}$ :

$$
\begin{aligned}
& \tilde{D}=\left[\begin{array}{ccc}
\tilde{y}_{11} & \cdots & \tilde{y}_{1 n} \\
\vdots & \vdots & \vdots \\
\tilde{y}_{m 1} & \cdots & \tilde{y}_{m n}
\end{array}\right] \\
& \tilde{w}=\left[\begin{array}{lll}
\tilde{w}_{1}, & \tilde{w}_{2}, \ldots, \tilde{w}_{n}
\end{array}\right]
\end{aligned}
$$

Triangular fuzzy numbers describe these linguistics variables as $\tilde{y}_{i j}=\left(a_{i j}, b_{i j}, c_{i j}\right)$ and $\tilde{w}_{j}=\left(w_{j 1}, w_{j 2}, w_{j 3}\right)$.

Step 4: The normalized fuzzy decision matrix is constructed from the fuzzy decision matrix defined in the above step. The equation is given below:

$$
\begin{gathered}
R=\left[\tilde{r}_{i j}\right]_{\mathrm{m} \times \mathrm{n}} \\
\tilde{r}_{i j}=\left(\frac{a_{i j}}{c_{j}^{*}}, \frac{b_{i j}}{c_{j}^{*}}, \frac{c_{i j}}{c_{j}^{*}}\right)
\end{gathered}
$$

where $c_{j}^{*}=\max _{i} c_{i j}$

Step 5: The next step is to calculate a weighted normalized fuzzy decision matrix through the equation given below:

$$
\begin{aligned}
\tilde{U}_{i j} & =\left[\tilde{w}_{j} \times \tilde{r}_{i j}\right] \mathrm{m} \times \mathrm{n} \\
i & =1, \ldots, m ; j=1, \ldots, n ;
\end{aligned}
$$

Step 6: When all the abovementioned calculations are performed, determine the fuzzy positive ideal solution as $F^{*}$ and fuzzy negative ideal solution as $F^{-} . F^{*}$ and $F^{-}$can be defined as follows:

$$
\begin{gathered}
F^{*}=\tilde{u}_{1}^{*}, \tilde{u}_{2}^{*}, \ldots, \tilde{u}_{n}^{*} \\
F^{-}=\tilde{u}_{1}^{-}, \tilde{u}_{2}^{-}, \ldots, \tilde{u}_{n}^{-}
\end{gathered}
$$

The value of $\tilde{u}_{j}^{*}=(1,1,1)$ and $\tilde{u}_{j}^{-}=(0,0,0), j=(1,2, \ldots, n)$. 
Step 7: In this step, the distance from the positive and negative ideal solution will be determined as follows:

$$
\begin{gathered}
S_{i} \text { steric }=\sum_{j=1}^{n} s\left(\tilde{u}_{i j}, \tilde{u}_{j}^{*}\right) \\
S_{i} \text { negative }=\sum_{j=1}^{n} s\left(\tilde{u}_{i j}, \tilde{u}_{j}^{-}\right)
\end{gathered}
$$

" $s$ )" is used to denote the distance between two fuzzy numbers.

Step 8: The closeness coefficient $C C_{i}$ is calculated for each alternative $i$ as follows:

$$
C C_{i}=\frac{S_{i} \quad \text { negative }}{S_{i} \quad \text { steric }+S_{i} \text { negative }}
$$

Step 9: Based on the closeness coefficient values, choose the alternative having the highest $C C_{i}$ value.

\subsection{Fuzzy VIKOR}

Using the VIKOR method under a fuzzy environment, the barriers toward implementation of RL can be evaluated. Steps involved in the calculation of fuzzy VIKOR are (Razi and Ali, 2018; Awan and Ali, 2019) as follws:

Steps 1-3: Similar to Steps 1-3 above, using input from experts, the decision matrix $\tilde{D}$ and weight vector $\tilde{w}$ are developed:

$$
\tilde{D}=\left[\begin{array}{ccc}
\tilde{y}_{11} & \cdots & \tilde{y}_{1 n} \\
\vdots & \vdots & \vdots \\
\tilde{y}_{m 1} & \cdots & \tilde{y}_{m n}
\end{array}\right] \tilde{w}=\left[\tilde{w}_{1}, \tilde{w}_{2}, \ldots, \tilde{w}_{n}\right]
$$

where $i=1, \ldots, m ; j=1, \ldots, n$.

Step 4: Use the $B N P_{i}$ formula to convert each fuzzy weight and rating into crisp values. The equation is given below:

$$
B N P_{i}=\frac{\left[\left(c_{i}-a_{i}\right)+\left(b_{i}-a_{i}\right)\right]}{3}+a_{i}, \quad i=1, \ldots, m
$$

Step 5: For all criterion rating, determine the best crisp value $f_{j}^{*}$ and $f_{j}^{-}$by using the relation given below:

$$
f_{j}^{*}=\left\{\begin{array}{cc}
\max _{i} E_{i j}, & \text { for benefit criteria } \\
\min _{i} E_{i j}, & \text { for cost criteria }
\end{array}\right\}
$$


$\underset{5,1}{\mathrm{JDAL}} \quad f_{j}^{-}=\left\{\begin{array}{ll}\min _{i} E_{i j}, & \text { for benefit criteria } \\ \max _{i} E_{i j}, & \text { for cost criteria }\end{array}\right\}$

Step 6: $S_{i}$ and $R_{i}$, the separation from fuzzy values, can be calculated as follows:

$$
\begin{aligned}
S_{i} & =\sum_{j=1}^{n} \cdot \frac{\tilde{w}_{j}^{*}\left(f_{j}^{*}-E_{i j}\right)}{f_{j}^{*}-f_{j}^{-}} \\
R_{i} & =\max _{j} \frac{\tilde{w}_{j}^{*}\left(f_{j}^{*}-E_{i j}\right)}{f_{j}^{*}-f_{j}^{-}}
\end{aligned}
$$

Step 7: In this step, the value of $Q_{i}$ will be determined using the following relation:

$$
Q_{i}=\frac{v\left(S_{i}-S^{*}\right)}{\left(S^{-}-S^{*}\right)}+\frac{(1-v)\left(R_{i}-R^{*}\right)}{\left(R^{-}-R^{*}\right)}
$$

where $S^{*}$ represents the minimum value of $S_{i}$, whereas $S$ represents the maximum value of $S_{i} \cdot R^{*}$ represents minimum, whereas $R^{-}$represents the maximum value of $R_{i}$. The value of $v$ is 0.5 , which is a weight for maximum group utility.

Step 8: Select the best alternative as a compromise solution after ranking the alternatives by sorting each $S, R$ and $Q$ value in ascending orders.

\section{Problem with fuzzy TOPSIS}

Both fuzzy VIKOR and fuzzy TOPSIS provide a ranking list. The VIKOR-based solution is considered as most feasible compared to the TOPSIS method because TOPSIS does not consider the relative importance of ideal solution distance (Zhang and Wei, 2013). Furthermore, fuzzy VIKOR is also preferred over TOPSIS because a compromise solution is given by it that provides an advantage over TOPSIS (Opricovic and Tzeng, 2004). Moreover, VIKOR considers the interrelation, whereas TOPSIS does not. The percentage of the problem solved is decreased when the number of criteria is increased as shown in earlier studies. Recent research uses fuzzy TOPSIS when comparing results with VIKOR, but it suggested that if the number of criteria increases, then the most preferred technique will be fuzzy VIKOR (Razi and Ali, 2018).

So, based on the abovementioned studies, we concluded that the fuzzy VIKOR approach is much more suitable as compared to TOPSIS. The results and discussions that follow are based on the findings from the fuzzy VIKOR approach. It is also recommended to not use TOPSIS and VIKOR simultaneously for future research.

\section{Results and discussion}

Fourteen criteria were considered in this study. All of the criteria were barriers, i.e. "negative attributes." The results derived from both fuzzy TOPSIS and fuzzy VIKOR are ranked in Table 5.

The overall weights assigned by decision-makers have also been used to find critical barriers toward the implementation of RL. Among the 14 criteria, the lack of recognition of competitive advantage to be gained through the process of RL was identified as the top 
barrier. Previous research studies also conclude that the main barrier toward the implementation of $\mathrm{RL}$ is the assumption of companies that the competitive advantage to be gained through RL is low (Bouzon et al., 2015b). The criterion ranked second is uncertainty related to the economic issues. This criterion is under the category of economic-related issues. It was identified to be most critical toward the implementation of RL in previous research, as the investment made for RL is considered not justifiable (Tan and Hosie, 2010). The major facilitator toward RL implementation was "supportive initiative for EOL." Rahman and Subramanian (2012) concluded that there are no policies devised regarding the implementation of RL for end-of-life products (Rahman and Subramanian, 2012). However, Pakistan's present government has started to take initiatives and devised some policies regarding sustainability issues. The government of Pakistan has initiated different projects to make the country green. Furthermore, most of the companies have also incorporated the concept of sustainability.

Table 6 given below shows the distance of alternatives from their ideal solution. The alternative "reuse" is ranked first. The experts judged reuse as the most feasible alternative because the value of $Q$ is at a minimum distance from zero. The same procedure is followed for the rest of the alternatives and ranked according to $Q$ values. The least important alternative is "repair." It does not mean that this alternative cannot be used, it means that this alternative will not have any significant effects on RL practice.

The results derived from fuzzy TOPSIS along with its closeness factors are given in Table 7.

\begin{tabular}{lll}
\hline Ranking & Fuzzy VIKOR & Fuzzy TOPSIS \\
\hline 1 & Reuse & Recycle \\
2 & Remanufacturing & Remanufacturing \\
3 & Refurbishment & Repair \\
4 & Recycle & Reuse \\
5 & Repair & Refurbishment
\end{tabular}

Identification of critical factors

Table 5.

Comparison of alternatives derived from fuzzy VIKOR and fuzzy TOPSIS

\begin{tabular}{lc}
\hline Alternative & $Q$ value \\
\hline Reuse & 0.37 \\
Recycle & 0.80 \\
Repair & 0.93 \\
Refurbishment & 0.61 \\
Remanufacturing & 0.50
\end{tabular}

Table 6.

$Q$ value of alternatives from fuzzy VIKOR

\begin{tabular}{lr}
\hline Alternative & CC values \\
\hline Recycle & 0.513925 \\
Repair & 0.503308 \\
Remanufacturing & 0.503323 \\
Reuse & 0.495811 \\
Refurbishment & 0.472739
\end{tabular}

Table 7.

$\mathrm{CC}$ values of fuzzy TOPSIS 
JDAL 5,1

106

This study presents an effort toward the implementation of RL in Pakistan. In our findings, the top-ranked alternative is "reuse." A product can be reused with a slight cleaning and without involving any production process. The lowest barrier identified through the rating of each alternative against criteria is government support toward activities involving the reuse of products. The criteria with the highest rating in reuse indicating a barrier were issues related to handling and storing of items, as this requires a substantial investment. The present government of Pakistan has initiated different programs toward making the country green. Moreover, young entrepreneurs in Pakistan have started to integrate the concept of preventing environmental pollution in their businesses. Through the energy audit, Pakistani entrepreneurs found that they can save up to $15 \%-25 \%$ in energy and power cost by reusing dumped products [5]. Despite this development, the reuse practices in Pakistan are still at a minor level as compared to other countries. A network for reusable items has been developed in the USA with factors including technical, economic, regulatory and behavioral (Park, 2014). Reuse as an alternative has also been given importance by Carrasco-Gallego et al. (2012). This research reviews several case studies that develop a network for reusable items such as wheelchairs, reusable glass bottles and a variety of trays, pallets and trolleys. However, other research studies conclude that difficulties that arise with reuse are timing, quantities and investment (Al-Salem et al., 2009).

Remanufacturing is the second-best alternative for RL practice. Motivating forces behind remanufacturing are environmental restrictions. As devised by the law, most of the companies in the present era are required to take back their products for remanufacturing (Heda et al., 2017). Previous research identified uncertainty regarding quality, quantity and timing from product returns as influencing the success of remanufacturing (Rogers and Tibben-Lembke, 1999b). These observations are consistent with our research. It seems that the lack of a system to monitor returns hurts the implementation of remanufacturing. To combat these problems, Jayaraman and Luo (2007) developed a model that determines the location for remanufacturing facilities and optimal quantities for remanufactured products and cores. Remanufacturing is also being given importance in Pakistan as the Islamabad Chamber of Commerce and Industry has started promoting the remanufacturing industry both for small- and medium-sized enterprises. The major reason behind this promotion is to overcome the problem of huge quantities of scrap in different areas and for achieving better economic value from scrap material [6]. RL practices in terms of remanufacturing have also been given importance in India as different models have been developed for profit maximization through the process of remanufacturing (Sasikumar and Kannan, 2009).

Refurbishment was ranked third and recycling was ranked fourth. Refurbishment means that products are brought up to a specific quality level. In recycling, the identity of the original product is lost as it is used in the production of new parts. Previous research has indicated that recycling is not effective when investment cost is high because of the requirement of advanced technological equipment (Fleischmann, 2001). Also, recycling is a concern with low-value products. In addition, volume uncertainty is high for recycling products. For these reasons, this practice has not been given much importance by some academies (Galbreth and Blackburn, 2006). To overcome issues in recycling, a Portuguese glass manufacturing company developed a scenario-based model for quantity and quality of returned products (Zeballos et al., 2012). There is also some serious concern regarding recycling in Pakistan. This practice in Pakistan has not been adopted at a greater level because there is a lack of proper infrastructure through which waste should be disposed of or sent for the process of recycling [7]. This is the major reason behind low practice of recycling as an alternative for RL in Pakistan. 
The lowest-ranked alternative in this study is "repair." Previous research indicated that the process of repair is very costly as different products have different needs regarding repair services (Fernández and Junquera, 2003). There are also different manners in which enterprises organize RL channels. These channels range from factory support to independent third parties and there is complexity in claiming which channel is best (Loomba and Nakashima, 2012). Also, in the case of Pakistan, no importance has been given to repair as compared to reuse and remanufacturing. Manufacturing organizations are faced with the problem of selecting which channel is the best to carry out repairing and these channels require investment at a larger level. Also, finding employees with the best technical skills and training staff for this practice requires considerable time and attention. We believe this is why this practice is highly neglected in the case of Pakistan.

\section{Conclusion}

This study attempts to cover the gap in the literature related to RL barriers. We address this gap by identifying barriers and prioritizing alternatives in a fuzzy environment for the manufacturing industry of Pakistan. Despite its long-term benefits, in most of the developing countries, RL concepts are considered an extra financial burden on the companies. Pakistan, being a developing country, is trying to stabilize its reviving economy by developing its infrastructure, information and communication technology and industrial sector through the China Pakistan Economic Corridor. However, the concept of RL is also gaining importance in developing countries like Pakistan because of its economic and social advantages. To find the barriers to RL, 14 criteria were used in this study to evaluate five alternatives: recycling, reuse, refurbishment, remanufacturing and repairing. To cope with these barriers, MCDM techniques are applied in this study, i.e. fuzzy VIKOR and fuzzy TOPSIS. The most feasible alternative is selected based on fuzzy VIKOR ranking. The results from fuzzy TOPSIS are limited because it does not consider the relative importance of the ideal solution. For this reason, the ranking given by fuzzy VIKOR is considered the most credible in this study. "Reuse" ranked first as the best alternative for RL according to fuzzy VIKOR. The process of reuse is most feasible because a product can be reused without involving any production or processing at a larger scale. Also, it has the advantage of operational effectiveness. Remanufacturing ranked the second-best alternative for RL in the case of Pakistan. The small and medium remanufacturing enterprises in Pakistan are growing at a rapid pace. Likewise, refurbishment ranked third and recycle ranked fourth. Repair ranked fifth as an alternative for RL in the case of Pakistan. The major reason is that the process of repair is costly. Also, there are multiple channels for repair that ranges from the company itself to third parties. These channels further complicate the implementation of repair. The fuzzy VIKOR ranking is also compared with the fuzzy TOPSIS in this study. In fuzzy TOPSIS, recycling ranked first, whereas repair ranked fifth. The findings of this study will assist managers in deploying the best practices concerning $\mathrm{RL}$ in the manufacturing sector of Pakistan. Manufacturing firms can also focus on the aim of improving their sustainability projects by using these RL activities as a pragmatic tool.

\section{Limitations and future line of research}

A few of the limitations of this study are the limited number of experts as respondents. The results of this research could have been obtained in a more refined form if the number of participants could be increased. More alternatives should be taken into consideration for a future line of research. It is further recommended that future research should focus
Identification of critical factors 
on a specific manufacturing industry to find the most attractive alternatives regarding RL implementation.

\section{Notes}

1. www.emergingpakistan.gov.pk/opportunities/punjab/manufacturing/

2. https://siteresources.worldbank.org/INTWDR2012/Resources/7778105-1299699968583/7786210-131593 6222006/Complete-Report.pdf

3. www.commonwealthofnations.org/sectors-pakistan/business/industry_and_manufacturing

4. https:/profit.pakistantoday.com.pk/2018/04/23/industrial-sector-grows-at-5-8pc-in-fy2018/

5. www.thenews.com.pk/print/201100-Adoption-of-waste-economy-in-Pakistan-to-save-money-environment

6. www.thenews.com.pk/archive/print/315271-icci-for-promoting-remanufacturing-industry

7. www.export.gov/article?id=Pakistan-Waste-Management

8. www.dawn.com/news/1352390

\section{References}

Abdulrahman, M.D., Gunasekaran, A. and Subramanian, N. (2014), "Critical barriers in implementing reverse logistics in the Chinese manufacturing sectors", International Journal of Production Economics, Vol. 147, pp. 460-471.

Ali, Y., Awan, M.A., Bilal, M., Khan, J., Petrillo, A. and Khan, A.A. (2019a), "Risk assessment of ChinaPakistan fiber optic project (CPFOP) in the light of multi-criteria decision making (MCDM)", Advanced Engineering Informatics, Vol. 40, pp. 36-45.

Ali, Y., Razi, M., De Felice, F., Sabir, M. and Petrillo, A. (2019b), "A VIKOR based approach for assessing the social, environmental and economic effects of 'smog' on human health", Science of the Total Environment, Vol. 650, pp. 2897-2905.

Ali, Y., Arif, S., Munir, F., Azeem, M.B. and Khan, A.U. (2020a), "Can India Pakistan sports promote peace? A MCDM approach", International Journal of the Analytic Hierarchy Process, Vol. 12 No. 1, pp. 1-23.

Ali, Y., Khan, A., Khan, G., Khan, A.U. and Ahmad, Z. (2020b), "Evaluation of effectiveness of fence on a country's border: a case study of Pak-Afghan border fence", Journal of International Migration and Integration, Vol. 12, pp. 1-22.

Al-Salem, S.M., Lettieri, P. and Baeyens, J. (2009), "Recycling and recovery routes of plastic solid waste (PSW): a review", Waste Management, Vol. 29 No. 10, pp. 2625-2643.

Awan, M.A. and Ali, Y. (2019), "Sustainable modeling in reverse logistics strategies using fuzzy MCDM: Case of China Pakistan economic corridor", Management of Environmental Quality: An International Journal, Vol. 30 No. 5, pp. 1132-1151.

Babar, A.H.K., Ali, Y. and Khan, A.U. (2020), "Moving toward green mobility: overview and analysis of electric vehicle selection, Pakistan a case in point", Environment, Development and Sustainability, Vol. 1 No. 1, pp. 1-18.

Bernon, M., Upperton, J., Bastl, M. and Cullen, J. (2013), "An exploration of supply chain integration in the retail product returns process", International Journal of Physical Distribution and Logistics Management, Vol. 43 No. 7, pp. 586-608.

Bouzon, M., Govindan, K. and Rodriguez, C.M.T. (2015a), "Reducing the extraction of minerals: reverse logistics in the machinery manufacturing industry sector in Brazil using ISM approach", Resources Policy, Vol. 46, pp. 27-36. 
Bouzon, M., Spricigo, R., Rodriguez, C.M., de Queiroz, A.A. and Cauchick Miguel, P.A. ( 2015b), "Reverse logistics drivers: empirical evidence from a case study in an emerging economy", Production Planning and Control, Vol. 26 No. 16, pp. 1368-1385.

Carrasco-Gallego, R., Ponce-Cueto, E. and Dekker, R. (2012), "Closed-loop supply chains of reusable articles: a typology grounded on case studies", International Journal of Production Research, Vol. 50 No. 19, pp. 5582-5596.

Carter, C.R. and Ellram, L.M. (1998), "Reverse logistics: a review of the literature and framework for future investigation", Journal of Business Logistics, Vol. 19 No. 1, p. 85.

Chang, T.H. (2014), "Fuzzy VIKOR method: a case study of the hospital service evaluation in Taiwan", Information Sciences, Vol. 271 No. 1, pp. 196-212.

Chen, C.T. (2000), "Extensions of the TOPSIS for group decision-making under fuzzy environment", Fuzzy Sets and Systems, Vol. 114 No. 1, pp. 1-9.

Daugherty, P.J., Autry, C.W. and Ellinger, A.E. (2001), "Reverse logistics: the relationship between resource commitment and program performance”, Journal of Business Logistics, Vol. 22 No. 1, pp. 107-123.

Daugherty, P.J., Richey, R.G., Genchev, S.E. and Chen, H. (2005), "Reverse logistics: superior performance through focused resource commitments to information technology", Transportation Research Part E: Logistics and Transportation Review, Vol. 41 No. 2, pp. 77-92.

Elomda, B.M., Hefny, H.A. and Hassan, H.A. (2013), "An extension of fuzzy decision maps for multicriteria decision-making”, Egyptian Informatics Journal, Vol. 14 No. 2, pp. 147-155.

Eltayeb, T.K., Zailani, S. and Ramayah, T. (2011), "Green supply chain initiatives among certified companies in Malaysia and environmental sustainability: Investigating the outcomes", Resources, Conservation and Recycling, Vol. 55 No. 5, pp. 495-506.

Erol, I., Velioğlu, M.N., Şerifoğlu, F.S., Büyüközkan, G., Aras, N., Çakar, N.D. and Korugan, A. (2010), "Exploring reverse supply chain management practices in Turkey", Supply Chain Management: An International Journal, Vol. 15 No. 1, pp. 43-54.

Fernández, I. and Junquera, B. (2003), "The role of reverse logistics in repair customer support. Two companies under test", Proceedings of QMOD Conference, CiteSeerX, Paris.

Figueira, J., Greco, S. and Ehrgott, M.M. (2004), Multiple Criteria Decision Analysis: State of the Art Surveys, Springer, New York, NY.

Fleischmann, M. (2001), Reverse Logistics Network Structures and Design, available at SSRN: https:// ssrn.com/abstract $=370907$

Fleischmann, M., Bloemhof-Ruwaard, J.M., Dekker, R., Van der Laan, E., Van Nunen, J.A. and Van Wassenhove, L.N. (1997), "Quantitative models for reverse logistics: a review”, European Journal of Operational Research, Vol. 103 No. 1, pp. 1-17.

Fleischmann, M., Krikke, H.R., Dekker, R. and Flapper, S.D.P. (2000), "A characterisation of logistics networks for product recovery”, Omega, Vol. 28 No. 6, pp. 653-666.

Fleischmann, M., Van Nunen, J.A. and Gräve, B. (2003), "Integrating closed-loop supply chains and spare-parts management at IBM", Interfaces, Vol. 33 No. 6, pp. 44-56.

Galbreth, M.R. and Blackburn, J.D. (2006), "Optimal acquisition and sorting policies for remanufacturing", Production and Operations Management, Vol. 15 No. 3, pp. 384-392.

González-Torre, P., Alvarez, M., Sarkis, J. and Adenso-Díaz, B. (2010), "Barriers to the implementation of environmentally oriented reverse logistics: evidence from the automotive industry sector", British Journal of Management, Vol. 21 No. 4, pp. 889-904.

Govindan, K., Soleimani, H. and Kannan, D. (2015), "Reverse logistics and closed-loop supply chain: a comprehensive review to explore the future", European Journal of Operational Research, Vol. 240 No. 3, pp. 603-626.

Guide, V.D.R., Jr and Van Wassenhove, L.N. (2001), "Managing product returns for remanufacturing", Production and Operations Management, Vol. 10 No. 2, pp. 142-155.

Identification of critical factors 


\section{JDAL 5,1}

Gunasekaran, A. and Ngai, E.W. (2012), "The future of operations management: an outlook and analysis", International Journal of Production Economics, Vol. 135 No. 2, pp. 687-701.

Heda, M.S. Shinde, M.Y. Somani, M.P. and Kulkarni, P.P. (2017), "Reverse logistics and remanufacturing in industry", International Research Journal of Engineering and Technology (IRJET), Vol. 4 No. 9.

Horvath, P.A., Autry, C.W. and Wilcox, W.E. (2005), "Liquidity implications of reverse logistics for retailers: a Markov chain approach”, Journal of Retailing, Vol. 81 No. 3, pp. 191-205.

Huang, M., Song, M., Lee, L.H. and Ching, W.K. (2013), “Analysis for strategy of closed-loop supply chain with dual recycling channel", International Journal of Production Economics, Vol. 144 No. 2, pp. 510-520.

Hung Lau, K. and Wang, Y. (2009), "Reverse logistics in the electronic industry of China: a case study", Supply Chain Management: An International Journal, Vol. 14 No. 6, pp. 447-465.

Hwang, C.L. and Yoon, K.P. (1981), Multiple Objective Decision Making-Methods and Applications: A State-of-the-Art Survey, Springer Science and Business Media, Vol. 164.

Jayaraman, V. and Luo, Y. (2007), "Creating competitive advantages through new value creation: a reverse logistics perspective", Academy of Management Perspectives, Vol. 21 No. 2, pp. 56-73.

Kannan, D., Diabat, A. and Shankar, K.M. (2014), "Analyzing the drivers of end-of-life tire management using interpretive structural modeling (ISM)", The International Journal of Advanced Manufacturing Technology, Vol. 72 Nos 9/12, pp. 1603-1614.

Kapetanopoulou, P. and Tagaras, G. (2011), "Drivers and obstacles of product recovery activities in the Greek industry", International Journal of Operations and Production Management, Vol. 31 No. 2, pp. 148-166.

Khan, F., Ali, Y. and Khan, A.U. (2020), "Sustainable hybrid electric vehicle selection in the context of a developing country", Air Quality, Atmosphere and Health, Vol. 1 No. 1, pp. 1-11.

Krikke, H. (2011), "Impact of closed-loop network configurations on carbon footprints: a case study in copiers”, Resource Conservation Recycling, Vol. 55 No. 12, pp. 1196-1205.

Kumar, S. and Putnam, V. (2008), "Cradle to cradle: reverse logistics strategies and opportunities across three industry sectors", International Journal of Production Economics, Vol. 115 No. 2, pp. 305-315.

Lamba, D., Yadav, D., Barve, A. and Panda, G. (2019), "Prioritizing barriers in reverse logistics of Ecommerce supply chain using fuzzy-analytic hierarchy process", Electronic Commerce Research, Vol. 20 No. 2, pp. 1-23.

Locke, K. and Golden-Biddle, K. (1997), "Constructing opportunities for contribution: structuring intertextual coherence and 'problematizing' in organizational studies", Academy of Management Journal, Vol. 40 No. 5, pp. 1023-1062.

Loomba, A.P. and Nakashima, K. (2012), "Enhancing value in reverse supply chains by sorting before product recovery", Production Planning and Control, Vol. 23 Nos 2/3, pp. 205-215.

Murphy, P.R. and Poist, R.F. (1989), "Management of logistical retromovements: an empirical analysis of literature suggestions", Journal of the Transportation Research Forum, Vol. 29 No. 1, pp. 177-184.

Mutha, A. and Pokharel, S. (2009), "Strategic network design for reverse logistics and remanufacturing using new and old product modules", Computers and Industrial Engineering, Vol. 56 No. 1, pp. 334-346.

Nădăban, S., Dzitac, S. and Dzitac, I.F. (2016), "Fuzzy topsis: a general view”, Procedia Computer Science, Vol. 91, pp. 823-831.

Oleveira, D., Luna, C.M. and Campos, L. (2019), "Understanding the Brazilian expanded polystyrene supply chain and its reverse logistics towards circular economy", Journal of Cleaner Production, Vol. 235, pp. 562-572. 
Opricovic, S. and Tzeng, G.H. (2004), "Compromise solution by MCDM methods: a comparative analysis of VIKOR and TOPSIS", European Journal of Operational Research, Vol. 156 No. 2, pp. 445-455.

Opricovic, S. (1998), "Multicriteria optimization of civil engineering systems", Faculty of Civil Engineering, Belgrade, Vol. 2 No. 1, pp. 5-21.

Park, J.Y. (2014), "Assessing determinants of industrial waste reuse: the case of coal ash in the United States", Resources, Conservation and Recycling, Vol. 92, pp. 116-127.

Phochanikorn, P., Tan, C. and Chen, W. (2019), "Barriers analysis for reverse logistics in Thailand's palm oil industry using fuzzy multi-criteria decision-making method for prioritizing the solutions”, Granular Computing, Vol. 5 No. 4, pp. 1-18.

Poist, R.F. (2000), "Development and implementation of reverse logistics", Programs Transportation Journal, Vol. 39 No. 3, p. 54.

Rahimifard, S., Coates, G., Staikos, T., Edwards, C. and Abu-Bakar, M. ( 2009), "Barriers, drivers and challenges for sustainable product recovery and recycling", International Journal of Sustainable Engineering, Vol. 2 No. 2, pp. 80-90.

Rahman, S. and Subramanian, N. (2012), "Factors for implementing end-of-life computer recycling operations in reverse supply chains", International Journal of Production Economics, Vol. 140 No. 1, pp. 239-248.

Razi, M. and Ali, Y. (2018), "Ranking renewable energy production methods based on economic and environmental criteria using multi-criteria decision analysis", Environment Systems and Decisions, Vol. 1 No. 1, pp. 1-16.

Richey, R., Daugherty, P., Genchev, S. and Autry, C. (2004), "Reverse logistics: the impact of timing and resource”, Journal of Business Logistics, Vol. 25 No. 2, pp. 229-250.

Rogers, D.S. and Tibben-Lembke, R.S. (1999a), "Reverse logistics': stratégies et techniques”, Logistique and Management, Vol. 7 No. 2, pp. 15-25.

Rogers, D.S. and Tibben-Lembke, R.S. (1999b), Going Backwards: reverse Logistics Trends and Practices, Reverse Logistics Executive Council, Pittsburgh, PA, Vol. 2.

Sajan, J. and Sridharan, R. (2015), "Modelling and analysis of network design for a reverse supply chain”, Journal of Manufacturing Technology Management, Vol. 26 No. 6, pp. 853-867.

Sasikumar, P. and Kannan, G. (2009), "Issues in reverse supply chain, part III: classification and simple analysis", International Journal of Sustainable Engineering, Vol. 2 No. 1, pp. 2-27.

Sharma, S.K., Panda, B.N., Mahapatra, S.S. and Sahu, S. (2011), "Analysis of barriers for reverse logistics: an Indian perspective", International Journal of Modeling and Optimization, Vol. 1 No. 2, pp. 101-106.

Somuyiwa, A.O. and Adebayo, I.T. (2014), "Empirical study of the effect of reverse logistics objectives on economic performance of food and beverages companies in Nigeria", International Review of Management and Business Research, Vol. 3 No. 3, p. 1484.

Srivastava, S.K. and Srivastava, R.K. (2006), "Managing product returns for reverse logistics", International Journal of Physical Distribution and Logistics Management, Vol. 36 No. 7, pp. 524-546.

Stock, J.R. and Mulki, J.P. (2009), "Product returns processing: an examination of practices of manufacturers, wholesalers/distributors, and retailers", Journal of Business Logistics, Vol. 30 No. 1, pp. 33-62.

Subramanian, N. and Ramanathan, R. (2012), "A review of applications of analytichierarchy process in operations management", International Journal of Production Economics, Vol. 138 No. 2, pp. 215-241.

Tan, A.W.K. and Hosie, P. (2010), "Reverse logistics operations in Singapore to support Asia Pacific regions", International Journal of Electronic Customer Relationship Management, Vol. 4 No. 2, pp. 196-208. 
JDAL

5,1
Thierry, M., Salomon, M., Van Nunen, J. and Van Wassenhove, L. (1995), "Strategic issues in product recovery management”, California Management Review, Vol. 37 No. 2, pp. 114-136.

Tibben-Lembke, R.S. and Rogers, D.S. (2002), "Differences between forward and reverse logistics in retail environment", Supply Chain Management: An International Journal, Vol. 7 No. 5, pp. 271-282.

Yavuz, M. (2016), "Equipment selection by using fuzzy TOPSIS method”, IOP Conference Series: Earth and Environmental Science, Vol. 44 No. 4.

Zeballos, L.J., Gomes, M.I., Barbosa-Povoa, A.P. and Novais, A.Q. (2012), "Addressing the uncertain quality and quantity of returns in closed-loop supply chains", Computers and Chemical Engineering, Vol. 47, pp. 237-247.

Zhang, N. and Wei, G. (2013), "Extension of VIKOR method for decision making problem based on hesitant fuzzy set", Applied Mathematical Modelling, Vol. 37 No. 7, pp. 4938-4947.

Zikopoulos, C. and Tagaras, G. (2007), "Impact of uncertainty in the quality of returns on the profitability of a single-period refurbishing operation", European Journal of Operational Research, Vol. 182 No. 1, pp. 205-225.

\section{Corresponding author}

Yousaf Ali can be contacted at: yousafkhan@giki.edu.pk

For instructions on how to order reprints of this article, please visit our website: www.emeraldgrouppublishing.com/licensing/reprints.htm

Or contact us for further details: permissions@emeraldinsight.com 